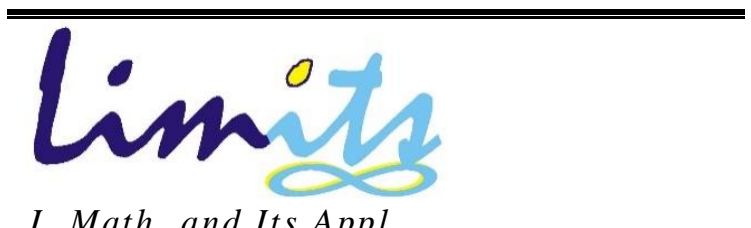

J. Math. and Its Appl.

ISSN: $1829-605 \mathrm{X}$

Vol. 9, No. 1, Mei 2012, 31-39

\title{
PENENTUAN KUANTITAS OPTIMAL DAN REORDER POINT PADA PERSEDIAAN SUKU CADANG DENGAN DISTRIBUSI GAMMA
}

\author{
Valeriana Lukitosari \\ Institut Teknologi Sepuluh Nopember \\ valeriana@matematika.its.ac.id
}

\begin{abstract}
Abstrak
Adanya pola demand dan lead time yang bervariasi mengakibatkan pentingnya pengelolaan suku cadang secara tepat. Penentuan kuantitas dan reorder point yang tepat sangat berpengaruh terhadap besarnya biaya persediaan suku cadang.

Model biaya persediaan dikembangkan dengan mempertimbangkan ketidakpastian demand. Pada penelitian ini, demand dipengaruhi adanya kerusakan pada peralatan. Model awal biaya persediaan didekati dengan distribusi gamma. Hasil pengembangan model dengan distribusi gamma menunjukkan bahwa reorder point persediaan suku cadang dipengaruhi nilai safety stock persediaan. Nilai safety stock bergantung pada ekspektasi permintaan selama lead time, sebesar parameter $\beta$ dan $\alpha$.

Penelitian ini juga menunjukkan bahwa model persediaan berdistribusi gamma dapat digunakan untuk mencari kuantitas optimal melalui biaya ekspektasi kekurangan persediaan.

Kata kunci: Kuantitas Optimal, Reorder Point, Distribusi Gamma
\end{abstract}

\section{Pendahuluan}

Demand suku cadang berbeda dengan demand material pada umumnya, biasanya dipengaruhi adanya kerusakan peralatan. Waktu yang dibutuhkan untuk pengadaan suku cadang mulai dari pemesanan hingga kedatangan disebut lead time. Waktu yang dibutuhkan dalam penyediaan suku cadang bisa sangat cepat atau sebaliknya mengalami kelambatan. Persediaan suku cadang menjadi masalah yang kompleks, terutama karena adanya pola permintaan yang intermittent atau lumpy [1], [8]. Pada permintaan intermittent adalah permintaan bersifat acak dengan beberapa periode tanpa permintaan. Sedangkan permintaan lumpy dalam beberapa periode tidak terdapat permintaan dan bersifat acak dalam jangka waktu yang panjang. 
Persediaan suku cadang memiliki ciri yang unik dibandingkan persediaan barang pada umumnya. Keunikan dari pola permintaan suku cadang yaitu waktu permintaan yang tidak beraturan membuat menetapkan pengadaan sulit dilakukan. Sehingga terbuka beberapa peluang untuk meneliti model persediaan suku cadang antara lain dengan melihat demand, lead time, distribusi kerusakan, dan pemberian garansi peralatan.

Banyak metode yang telah dikembangkan dalam meramalkan persediaan suku cadang hingga saat ini, antara lain: moving average, exponential smoothing, dan analisa regresi [4],[6],[7]. Sedangkan beberapa penelitian [5],[8], yang membahas mengenai model persediaan suku cadang menitikberatkan permintaan barang selama lead time menggunakan distribusi normal.

Berbeda dengan penelitian-penelitian yang sudah dilakukan, maka pada penelitian ini menitikberatkan pada peluang stockout persediaan suku cadang dan distribusi kerusakan menggunakan distribusi gamma. Sifat unik dari kerusakan suku cadang membutuhkan penanganan secara khusus. Model persediaan yang sesuai dengan karakteristik kerusakan akan memberikan kemudahan pihak manajemen dalam mengambil keputusan yang tepat [3].

\section{Model Persediaan Suku Cadang}

Pada model persediaan suku cadang pada penelitian ini mempertimbangkan terjadinya stockout. Ketika terjadi stockout, biaya meningkat karena ada tambahan stock cadangan pada penyimpanan. Pada model ini, juga ada tambahan biaya mengenai biaya stockout dari persediaan suku cadang. Total biaya persediaan tahunan untuk model ini adalah sebagai berikut [9]:

$$
T C=H c+P c+R c+S c
$$

dimana:

$H c$ : Total biaya penyimpanan suku cadang

$P c$ : Total biaya pembelian suku cadang

$R c$ : Total biaya pemesanan suku cadang

Sc : Total biaya stockout persediaan suku cadang

Pada model persediaan suku cadang tanpa mempertimbangkan backorder, rata-rata persediaan ditulis dengan $\frac{Q}{2}$. Sedangkan pada model persediaan suku cadang dengan mempertimbangkan backorder memerlukan safety stock sehingga rata-rata persediaan menjadi $\frac{Q}{2}+S$.

Untuk menghitung safety stock sebagai berikut:

dengan:

$$
S=\int_{0}^{\infty}(R-M) f(M) d M
$$

$S:$ Safety stock (stok pengaman)

$R:$ Reorder Point (titik pemesanan kembali)

$M$ : Permintaan selama lead time

$\bar{M}$ : Rata - rata permintaan selama lead time 
Pada [9] dan [10] didefinisikan rata - rata dari fungsi kepadatan peluang $f(M)$ yang kontinu adalah:

$$
E(M)=\int_{-\infty}^{\infty} M f(M) d M
$$

Dengan fungsi kepadatan peluang $f(M)$ sebagai berikut:

$$
\int_{-\infty}^{\infty} f(M) d M=1
$$

Karena $\mathrm{M}$ menyatakan variabel acak besarnya permintaan suku cadang selama lead time yang mendefinisikan $M \geq 0$, maka rata - rata dari fungsi kepadatan peluang dan fungsi kepadatan peluang dapat ditulis menjadi:

$$
\begin{aligned}
& E(M)=\int_{0}^{\infty} M f(M) d M \\
& \int_{0}^{\infty} f(M) d M=1
\end{aligned}
$$

Sehingga diperoleh safety stock dari permintaan yaitu:

$$
\begin{aligned}
S & =\int_{0}^{\infty}(R-M) f((M) d M \\
& =\int_{0}^{\infty} R f(M) d M-\int_{0}^{\infty} M f(M) d M \\
& =R \int_{0}^{\infty} f(M) d M-\int_{0}^{\infty} M f(M) d M \\
& =R-E(M)
\end{aligned}
$$

\section{Pengembangan Model dengan Distribusi Gamma}

Demand yang terjadi pada persediaan suku cadang pada umumnya disebabkan adanya kerusakan suku cadang peralatan. Salah satu distribusi kerusakan yang dapat digunakan adalah distribusi gamma. Distribusi gamma merupakan distribusi kontinu yang dapat menggambarkan umur hidup suku cadang, lead time dan waktu servis. Fungsi gamma didefinisikan sebagai berikut [2]:

$$
\Gamma(\alpha)=\int_{0}^{\infty} t^{\alpha-1} e^{-t} d t \quad \text { untuk } \alpha>0 .
$$

Peubah acak kontinu $T$, mempunyai distribusi gamma dengan parameter $\alpha$ dan $\beta$. Jika fungsi padat peluangnya berbentuk [2]:

$$
\begin{array}{ll}
f(t)=\left\{\begin{array}{ll}
\frac{1}{\beta^{\alpha} \Gamma(\alpha)} t^{\alpha-1} e^{-\frac{t}{\beta}} & \text { untuk } t \geq 0 \\
0 & \text { yang lain }
\end{array} \text { dengan } \beta>0 \text { dan } \alpha>0\right. &
\end{array}
$$

Untuk menghitung $E(M)$ menggunakan distribusi gamma diuraikan sebagai berikut:

$$
\begin{aligned}
E(M) & =\int_{0}^{\infty} M f(M) d M \\
& =\int_{0}^{\infty} M \frac{1}{\beta^{\alpha} \Gamma(\alpha)} M^{\alpha-1} \exp \left(-\frac{M}{\beta}\right) d M \\
& =\frac{1}{\beta^{\alpha} \Gamma(\alpha)} \int_{0}^{\infty} M^{(1+\alpha)-1} \exp \left(-\frac{M}{\beta}\right) d M
\end{aligned}
$$




$$
\begin{aligned}
& =\frac{\beta^{1+\alpha} \Gamma(1+\alpha)}{\beta^{\alpha} \Gamma(\alpha)} \int_{0}^{\infty} \frac{1}{\beta^{1+\alpha} \Gamma(1+\alpha)} M^{(1+\alpha)-1} \exp \left(-\frac{M}{\beta}\right) d M \\
& =\frac{\beta^{1+\alpha} \Gamma(1+\alpha)}{\beta^{\alpha} \Gamma(\alpha)}=\beta \frac{\alpha \Gamma(\alpha)}{\Gamma(\alpha)}=\beta \alpha
\end{aligned}
$$

Biaya penyimpanan dapat ditulis dengan:

$$
\begin{aligned}
H c & =h\left(\frac{Q}{2}+S\right) \\
& =h\left(\frac{Q}{2}+R-E(M)\right)=h\left(\frac{Q}{2}+R-\beta \alpha\right)
\end{aligned}
$$

\subsection{Biaya Kekurangan Persediaan Suku Cadang}

Biaya kekurangan selama lead time lebih besar dari reorder point untuk menutupi kekurangan sebelumnya. Sehingga dapat ditulis sebagai berikut:

$$
E(M)= \begin{cases}0 & \text { untuk } M \leq R \\ M-R & \text { untuk } M>R\end{cases}
$$

Distribusi kebutuhan suku cadang selama lead time adalah distribusi gamma, maka didapatkan ekspektasi kekurangan persediaan adalah:

$$
\begin{aligned}
E(M>R) & =\int_{0}^{R}(M>R) f(M) d M+\int_{R}^{\infty}(M>R) f(M) d M \\
& =0+\int_{R}^{\infty}(M-R) f(M) d M \\
& =\int_{R}^{\infty}(M-R) f(M) d M
\end{aligned}
$$

Karena $M \sim \operatorname{GAM}(\beta, \alpha)$ maka p.d.f

$$
f(M)=\frac{1}{\beta^{\alpha} \Gamma(\alpha)} M^{\alpha-1} \exp ^{\left(-\frac{M}{\beta}\right)}
$$

Ekspektasi kekurangan persediaan berdistribusi gamma menyebabkan persamaan (9) menjadi:

$$
\begin{aligned}
E(M>R) & =\int_{R}^{\infty}(M-R) \frac{1}{\beta^{\alpha} \Gamma(\alpha)} M^{\alpha-1} \exp ^{\left(-\frac{M}{\beta}\right)} d M \\
& =\int_{R}^{\infty} M \frac{1}{\beta^{\alpha} \Gamma(\alpha)} M^{\alpha-1} \exp ^{\left(-\frac{M}{\beta}\right)} d M-\int_{R}^{\infty} R \frac{1}{\beta^{\alpha} \Gamma(\alpha)} M^{\alpha-1} \exp ^{\left(-\frac{M}{\beta}\right)} d M \\
& =\frac{1}{\beta^{\alpha} \Gamma(\alpha)} \int_{R}^{\infty} M^{(1+\alpha)-1} \exp ^{\left(-\frac{M}{\beta}\right)} d M-\frac{R}{\beta^{\alpha} \Gamma(\alpha)} \int_{R}^{\infty} M^{\alpha-1} \exp ^{\left(-\frac{M}{\beta}\right)} d M
\end{aligned}
$$

Penyelesaian dari persamaan (10) dengan $x=\frac{M}{\beta}$ adalah:

$$
\begin{gathered}
=\frac{1}{\beta^{\alpha} \Gamma(\alpha)} \int_{R}^{\infty} M^{(1+\alpha)-1} \exp ^{\left(-\frac{M}{\beta}\right)} d M-\frac{R}{\beta^{\alpha} \Gamma(\alpha)} \int_{R}^{\infty}(\beta x)^{\alpha-1} \exp ^{(-x)} \beta d x \\
=\frac{\beta^{\alpha}}{\beta^{\alpha} \Gamma(\alpha)} \int_{R / \beta}^{\infty} x^{(1+\alpha)-1} \exp ^{-x} d x-\frac{R \beta^{\alpha}}{\beta^{\alpha} \Gamma(\alpha)} \int_{R}^{\infty} x^{\alpha-1} \exp ^{(-x)} d x \\
=\frac{\beta^{\alpha}}{\beta^{\alpha} \Gamma(\alpha)} \Gamma\left(1+\alpha, \frac{R}{\beta}\right)-\frac{R \beta^{\alpha}}{\beta^{\alpha} \Gamma(\alpha)} \Gamma\left(\alpha, \frac{R}{\beta}\right) \\
=\frac{\beta^{\alpha} \Gamma\left(1+\alpha, \frac{R}{\beta}\right)}{\beta^{\alpha} \Gamma(\alpha)}-\frac{R \beta^{\alpha} \Gamma\left(\alpha, \frac{R}{\beta}\right)}{\beta^{\alpha} \Gamma(\alpha)} \\
=\frac{\Gamma\left(1+\alpha, \frac{R}{\beta}\right)}{\Gamma(\alpha)}-\frac{R \Gamma\left(\alpha, \frac{R}{\beta}\right)}{\Gamma(\alpha)} \\
=\frac{\Gamma\left(1+\alpha, \frac{R}{\beta}\right)-R \Gamma\left(\alpha, \frac{R}{\beta}\right)}{\Gamma(\alpha)}
\end{gathered}
$$

Besarnya biaya stockout persediaan suku cadang dapat dirumuskan sebagai berikut: 


$$
S c=b \frac{D}{Q} E(M>R)=b \frac{D}{Q}\left(\frac{\Gamma\left(1+\alpha, \frac{R}{\beta}\right)-R \Gamma\left(\alpha, \frac{R}{\beta}\right)}{\Gamma(\alpha)}\right)
$$

Sehingga didapatkan total biaya persediaan suku cadang dengan mempertimbangkan terjadinya stockout dengan distribusi gamma adalah:

$$
T C=H c+P c+R c+S c
$$

Biaya kekurangan persediaan suku cadang dapat diperoleh dengan persamaan:

$T C=h\left(\frac{Q}{2}+R-\beta \alpha\right)+p D+A \frac{D}{Q}+b \frac{D}{Q}\left(\frac{\Gamma\left(1+\alpha, \frac{R}{\beta}\right)-R \Gamma\left(\alpha, \frac{R}{\beta}\right)}{\Gamma(\alpha)}\right)$

\subsection{Kuantitas Pemesanan Optimal}

Kuantitas pemesanan suku cadang yang optimal diperoleh dengan menurunkan persamaan total biaya persediaan terhadap kuantitas.

$\frac{\partial T C(Q, R)}{\partial Q}=0$

$$
\begin{aligned}
& \frac{\partial T C(Q, R)}{\partial Q}=\frac{\partial}{\partial Q}\left(h\left(\frac{Q}{2}+R-\beta \alpha\right)+p D+A \frac{D}{Q} b \frac{D}{Q}\left(\frac{\Gamma\left(1+\alpha, \frac{R}{\beta}\right)-R \Gamma\left(\alpha, \frac{R}{\beta}\right)}{\Gamma(\alpha)}\right)\right) \\
& \frac{\partial T C(Q, R)}{\partial Q}=\frac{h}{2}+A D\left(-\frac{1}{Q^{2}}\right)+b D\left(-\frac{1}{Q^{2}}\right)\left(\frac{\Gamma\left(1+\alpha, \frac{R}{\beta}\right)-R \Gamma\left(\alpha, \frac{R}{\beta}\right)}{\Gamma(\alpha)}\right) \\
& \frac{\partial T C(Q, R)}{\partial Q}=\frac{h}{2}+\left(-\frac{1}{Q^{2}}\right)\left(A D+b D\left(\frac{\Gamma\left(1+\alpha, \frac{R}{\beta}\right)-R \Gamma\left(\alpha, \frac{R}{\beta}\right)}{\Gamma(\alpha)}\right)\right) \\
& 0=\frac{h}{2}+\left(-\frac{1}{Q^{2}}\right)\left(A D+b D\left(\frac{\Gamma\left(1+\alpha, \frac{R}{\beta}\right)-R \Gamma\left(\alpha, \frac{R}{\beta}\right)}{\Gamma(\alpha)}\right)\right) \\
& \frac{h}{2}=\frac{1}{Q^{2}}\left(A D+b D\left(\frac{\Gamma\left(1+\alpha, \frac{R}{\beta}\right)-R \Gamma\left(\alpha, \frac{R}{\beta}\right)}{\Gamma(\alpha)}\right)\right)
\end{aligned}
$$

Sehingga diperoleh nilai optimal $Q$ :

$$
Q^{2}=\frac{2\left(A D+b D\left(\frac{\Gamma\left(1+\alpha, \frac{R}{\beta}\right)-R \Gamma\left(\alpha, \frac{R}{\beta}\right)}{\Gamma(\alpha)}\right)\right)}{2\left(A D+b D\left(\frac{\Gamma\left(1+\alpha, \frac{R}{\beta}\right)-R \Gamma\left(\alpha, \frac{R}{\beta}\right)}{\Gamma(\alpha)}\right)\right)}
$$




$$
=\sqrt{\frac{2 D(A+b E(M>R))}{h}}
$$

Karena $Q^{*}>0$ maka:

$$
Q^{*}=\sqrt{\frac{2 D\left(A+b\left(\frac{\Gamma\left(1+\alpha, \frac{R}{\beta}\right)-R \Gamma\left(\alpha, \frac{R}{\bar{\beta}}\right)}{\Gamma(\alpha)}\right)\right)}{h}}
$$

\subsection{Reorder Point}

Reorder point dari suku cadang diperoleh dari persamaan (13) dengan menurunkan persamaan total biaya persediaan suku cadang dengan mempertimbangkan terjadinya stockout terhadap variabel $R$.

$$
\begin{aligned}
& \frac{\partial T C(Q, R)}{\partial R}=0 \\
& \frac{\partial T C(Q, R)}{\partial R}=\frac{\partial}{\partial R}\left(h\left(\frac{Q}{2}+R-\beta \alpha\right)+p D+A \frac{D}{Q}+b \frac{D}{Q} E(M>R)\right) \\
& \frac{\partial T C(Q, R)}{\partial R}=h+b \frac{D}{Q}\left(\frac{\partial}{\partial R} E(M>R)\right)
\end{aligned}
$$

dengan:

$$
\begin{aligned}
\frac{\partial}{\partial R} E(M>R)= & \frac{\partial}{\partial R}\left(\int_{R}^{\infty}(M-R) f(M) d M\right) \\
& =\frac{\partial}{\partial R}\left(\int_{R}^{\infty} M f(M) d M-\int_{R}^{\infty} R f(M) d M\right) \\
& =\frac{\partial}{\partial R}\left(\int_{R}^{\infty} M f(M) d M\right)-\frac{\partial}{\partial R}\left(\int_{R}^{\infty} R f(M) d M\right) \\
& =-\int_{R}^{\infty} f(M) d M \\
& =-P(M>R)
\end{aligned}
$$

Sehingga,

$$
\begin{gathered}
\frac{\partial T C(Q, R)}{\partial R}=h-b \frac{D}{Q} P(M>R) \\
0=h-b \frac{D}{Q} P(M>R) \\
b \frac{D}{Q} P(M>R)=h \\
P(M>R)=\frac{h Q}{b D}
\end{gathered}
$$

Dimana $P(M>R)$ merupakan probabilitas dari kekurangan persediaan yang optimal. Nilai probabilitas kekurangan persediaan ini digunakan untuk mencari nilai safety factor $(Z)$ pada tabel Z. Sehingga didapatkan nilai reorder point yang optimal yaitu: $R=E(M)+Z S_{d l}$.

\section{Kesimpulan}

Pengelolaan persediaan suku cadang harus dilakukan secara tepat terutama karena adanya ketidakpastian demand. Demand yang dipengaruhi adanya kerusakan pada peralatan didekati dengan distribusi gamma. Nilai reorder point dipengaruhi nilai safety stock persediaan. Nilai safety stock bergantung pada ekspektasi permintaan selama lead time, sebesar parameter $\beta$ dan $\alpha$. 
Penelitian ini juga menunjukkan bahwa model persediaan berdistribusi gamma dapat digunakan untuk mencari besarnya total biaya stockout yaitu besarnya biaya ekspektasi kekurangan persediaan.

\section{Daftar Pustaka}

[1] Bacchetti, A. dan Saccani, N. "Spare parts classification and demand forecasting for stock control: Investigating the gap between research and practice". Omega, Vol. 40, Iss. 6, hal 722-737, 2011.

[2] Bain, L. J., dan Engelhardt, M. Introduction To Probability And Mathematical Statistics. United States of America: Duxbury Thomson Learning, 1992.

[3] Driessen, M.A., Arts, J.J., van Houtum, G.J., Rustenburg, W.D., dan Huisman, B. "Maintenance spare parts planning and control: A framework for control and agenda for future research". Beta Working Paper series, 2010.

[4] Ghobbar, A.A. dan Friend, C.H. "Evaluation of forecasting methods for intermittent parts demand in the field of aviation: a predictive model". Computers \& Operations Research, Vol. 30, hal. 2097-2114, 2003.

[5] Jin, T. dan Liao, H. "Spare parts inventory control considering stochastic growth of an installed base". Computers \& Industrial Engineering, 56, hal. 452-460, 2009.

[6] Kaldchschmidt, M., Zotteri, G., dan Verganti, R. "Inventory management in a multi-echelon spare parts supply chain". International Journal of Production Economics, 81, hal. 397-413, 2003.

[7] Kennedy, W.J., Patterson, J.D., dan Fredendall, L.D. "An overview of recent literature on spare parts inventories". International Journal of Production Economics, 76, hal. 201-215, 2002.

[8] Strijbosch, L. W. G., Heuts, dan Van Der Scoot. "Improved spare parts inventory management: A case study". Center Discussion Paper, Vol.135, 1998.

[9] Tersine, Richard J. Principles of Inventory and Materials Management. Fourth Edition. Prentice-Hall, New Jersey, 1994.

[10] Zhou, Y., \& Zhao, X. "A two-demand-class inventory system with lostsales and backorders". Operations Research Letters, Vol. 38, Issue 4, hal. 261-266, 2010. 